\title{
Formulation and evaluation of propolis extracts based shampoo on dandruff causing bacteria
}

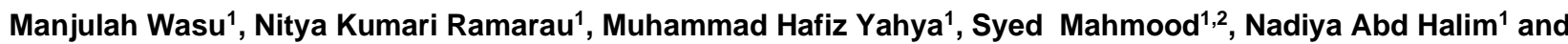 \\ Rajaletchumy Veloo Kutty ${ }^{1,2 *}$
}

${ }^{1}$ Faculty of Engineering Technology, Universiti Malaysia Pahang, 26300 Kuantan, Pahang, Malaysia.

${ }^{2}$ Center of Excellence for Advanced Research in Fluid Flow, University Malaysia Pahang

26300, Kuantan, Pahang, Malaysia.

Email: vrajaletchumy@ump.edu.my

Received 12 February 2019; Received in revised form 14 June 2019; Accepted 4 July 2019

\begin{abstract}
Aim: Dandruff is characterized by the white flakes in the hairs and can be caused by dry skin and mainly by fungal growth of Malassezia yeasts. To treat this condition mainly synthetic type of active ingredient shampoos are used which gave severe adverse effect toward users like hair fall and weakening of the hair roots. In this study, we formulate a shampoo containing an active ingredient "Propolis" an antimicrobial agent which is also known as bee glue. Formed by the combination of bee wax and flower exudate collected from the flower bud.

Methodology and results: In this study, propolis extracts have been used as the antimicrobial agent in the shampoo formulation for treating dandruff-causing bacteria, Staphylococcus aureus. Interestingly, the developed propolis shampoo showed is 10 -fold more effective against $S$. aureus compared to the propolis extracts alone. This is due to the presence of Tween 80 as the surfactant used in the formulation which adds to this antibacterial effect. The formulated shampoo was also compared with the commercially available shampoo (Safi Shayla brand) for physicochemical properties. Overall evaluation of the shampoo with propolis found to have $\mathrm{pH}(6-7)$, good foaming ability, less wetting time, a good percentage of solid content and viscosity. Also, the formulated shampoo has greater stability under accelerated room temperature and accelerated the ageing condition.

Conclusion, significance and impact of study: This study demonstrated the propolis extracted can be used as a potential antimicrobial agent. As it came from the natural resource the acceptance will high among the consumers.
\end{abstract}

Keywords: Propolis, herbal shampoo, antimicrobial, physico-chemical properties

\section{INTRODUCTION}

Dandruff is the most common scalp disorder that mostly affects adults (Borda and Wikramanayake, 2015). It can be said that dandruff is a condition on the scalp where white flakes can be seen on the hair which causes itchiness (Chaijan et al., 2018). Dandruff is a group of corneocytes, where they retained a large cohesion between them and which become unattached from the stratum corneum surface. The main causes of dandruff on the human scalp are due to the presence of oils and dirt in the surrounding air and also the growth of bacteria such as Staphylococcus aureus, Propionibacterium sp. and fungi, Malassezia sp. (Honnavar et al., 2017). There are various types of anti-dandruff shampoos are available in the market where mostly employed chemicals as active ingredients to treat the bacteria or yeast on the scalp. Some of the chemical ingredients used in the synthetic antidandruff shampoo resulting in baldness, dryness of hairs, irritation to scalp and eyes (Al Badi and Khan, 2014). To overcome this problem, herbal medicine was chosen as an active ingredient in shampoo formulation to treat dandruff and protect the scalp. There are large numbers of herbal drugs extracted from plants are reported to have medical benefits. Among them, propolis which is also known as bee glue is a resinous substance that is synthesized by honeybees from substance collected from tree buds, saps, mucilage's, lattices and other plant sources. In the ancient time, propolis has been used in the traditional medicine due to its biological properties that rich in phenolic acids, flavonoids, aromatic acids and diterpenoid acids (Elnakady et al., 2017). Propolis had shown an antifungicidal activity for Malassezia pachydermatis and antibacterial activities for S. aureus and S. intermedius (Cardoso et al., 2010).

There are many applications of propolis mostly in the biomedical due to a variety of biological properties. This is because propolis has been claimed to have antiviral, 
antibacterial, anti-inflammatory and antifungal activities. However, scientific researches on propolis are limited especially studies of propolis for the use in a topical application, lotion for healing septic wounds (Othman et al., 2016) and also the use in creams or ointments for curing cold sores (Sosmowski, 1983).

There is much research that shown that propolis exhibits antibacterial activity on some bacteria such as Candida albicans, S. aureus, and Escherichia coli (Chen et al., 2018). Propolis extracted using ethanol had shown high antibacterial property against a type of Gram-positive bacteria compared to Gram-negative bacteria and yeast (Silici and Kutluca, 2005). Even though extracted raw propolis has shown significant killing effects on the bacteria, there is a need to identify the effectiveness of propolis based shampoo in combat dandruff problem. At the outset of this study, only a handful of publications have been reported on the possible use of propolis as an antidandruff agent in shampoo. Thus, this study is to further explore on propolis usage as an active ingredient in antidandruff shampoo.

In this paper, we have formulated propolis based shampoo to evaluate and compare the physicochemical properties, stability, cleaning performances with commercial synthetic shampoo. We also evaluated the antibacterial effect of the formulated shampoo on Grampositive bacteria, $S$. aureus which is one of the dandruffcausing bacteria in humans.

\section{MATERIALS AND METHODS}

\section{Materials}

Raw propolis was directly collected from hives of stingless bees located in Kuantan, Malaysia. Ethylenediaminetetraacetic acid (EDTA), Tween 80, sodium carboxymethyl cellulose, sodium benzoate, citric acid, DMSO, ethanol, hexane, paraffin wax and nutrient agar were purchased from Sigma-Aldrich (USA). Coconut oil and SAFI Shayla - antidandruff shampoo was bought from the market. Staphylococcus aureus strain was obtained from the Centre Laboratory of Universiti Malaysia Pahang.

\section{Preparation of propolis extract}

Crude propolis pieces were grounded into a fine powder by utilizing a hammer. The crude propolis was kept under $-20{ }^{\circ} \mathrm{C}$. Then, the raw propolis powder was dried using the freeze-drying method before it was used for further processes. Ten gram of propolis powder was mixed with $100 \mathrm{~mL}$ of $70 \%$ ethanol solvent in a conical flask for $3 \mathrm{~min}$ at room temperature. The propolis with ethanol solvent was left overnight at room temperature in an incubator with a speed of $120 \mathrm{rpm}$.

\section{Purification of propolis extract}

The suspension prepared in previous paragraph was filtered through Whatman No. 1 filter paper. The filtrate solution after the filtration process was kept on a dark and airtight sealed bottle. This filtered solution was then concentrated using a rotary evaporator with a rotation speed of $80 \mathrm{rpm}$ and a temperature of $40{ }^{\circ} \mathrm{C}$. Finally, the propolis extract was freeze-dried under $72 \mathrm{mT}$ pressure at $-98.4{ }^{\circ} \mathrm{C}$ using VirTis Benchtop Pro freeze dryer (SP Scientific, New York, United States).

\section{Formulation of the herbal shampoo}

Table 1 shows formulations for an anti-dandruff shampoo with and without propolis extract, SP and SWP respectively. The shampoos were formulated by mixing the ingredients according to the proportions as stated in Table 1. The propolis powder was dissolved with Tween 80 in a beaker. In another beaker, the carboxymethyl cellulose which is the thickener was added drop by drop into a beaker that contains required water for the formulation in order to avoid clumping. Both of these mixtures were combined then sodium benzoate and EDTA were added together. The combinations were mixed and stirred continuously by using a homogenizer until the homogenous mixture was formed. The $\mathrm{pH}$ of the mixture was modified by adding a sufficient quantity of citric acid solution until the $\mathrm{pH}$ value lies between $\mathrm{pH} 5$ to $\mathrm{pH}$ 7. Developed shampoos (SP and SWP) were stored in a suitable container and used for further evaluations. In this study, commercial antidandruff shampoo SAFI Shayla (SAFI) was used as a comparison.

\section{Evaluation of shampoo formulation}

\section{Organoleptic studies}

The formulated antidandruff shampoo from propolis extract (SP) was evaluated for the colour, odour and texture. These characteristics of formulated antidandruff shampoo from propolis extract were compared with the commercial shampoo (SAFI) and with the formulated antidandruff shampoo without containing propolis extract (SWP).

\section{(i) Determination of $\mathrm{pH}$}

Ten percent $(\mathrm{v} / \mathrm{v})$ shampoo solution was prepared by mixing $10 \mathrm{~mL}$ of formulated anti-dandruff shampoo from propolis extract (SP) into $90 \mathrm{~mL}$ of distilled water in a beaker. The $10 \% \mathrm{v} / \mathrm{v}$ of shampoo solution in distilled water was tested for $\mathrm{pH}$ value by using $\mathrm{pH}$ meter at room temperature. The reading of the $\mathrm{pH}$ meter was observed and recorded. These steps were repeated for commercial shampoo SAFI Shayla (SAFI) and formulated antidandruff shampoo without propolis extract (SWP).

(ii) Determination of the percentage of solid content

The clean and dry evaporating dish was weighed. Four gram of SP shampoo was placed on the previous evaporating dish and weighed. The shampoo with the 
evaporating dish was weighed again to confirm the exact weight of the shampoo. The shampoo on the evaporating dish was placed on the hot plate at $100{ }^{\circ} \mathrm{C}$ and was evaporated until the liquid portion of shampoo evaporated. The weight and the percentage of the solid content of shampoo after complete drying were calculated. These steps were repeated for SWP and SAFI. Percentage of solid content was calculated by using equation below:

solid content $(\%)=[($ Weight of dried shampoo/ Initial weight of shampoo) $\times 100$ ]

(iii) Test to evaluate foaming ability and foaming stability

A $50 \mathrm{~mL}$ of the $1 \%$ SP sample was prepared by adding $0.5 \mathrm{~mL}$ of shampoo with $49.5 \mathrm{~mL}$ of distilled water. Fifty millilitre of $1 \%$ shampoo solution was put into a $250 \mathrm{~mL}$ graduated cylinder. Cylinder shake method was used for determining foaming ability. The graduated cylinder was covered with hand and was shaken for 10 times. The total volume of foam contents after $1 \mathrm{~min}$ was recorded. The volume of foam at $1 \mathrm{~min}$ intervals for $4 \mathrm{~min}$ was observed and recorded. These steps were repeated for SAFI and SWP.

\section{(iv) Viscosity test}

The viscometer (Brookfield) with different spindle speeds from $1 \mathrm{rpm}$ to $100 \mathrm{rpm}$ was used to determine the viscosity of the shampoo. Spindle CCT 25 was used to measure the viscosity of the shampoo. The temperature and size of the container were kept constant throughout the study. These steps were repeated for SWP and SAFI.

\section{(v) Wetting time test}

One percent $(1 \% \mathrm{v} / \mathrm{v}) \mathrm{SP}$ sample solution was prepared by mixing $1 \mathrm{~mL}$ of the SP sample into $99 \mathrm{~mL}$ of distilled water in a beaker. The filter paper was cut into 1-inch diameter discs. The surface of the disc was placed on the surface of $1 \%$ SP shampoo solution and the stopwatch was started to record the wetting time. The time taken for the disc to start sinking was observed and noted as the wetting time. These steps were repeated for SWP and SAFI.

\section{(vi) Cleaning ability test}

The cleaning test was done on $5 \mathrm{~g}$ wool yarn. The wool yarn was soaked in water for $24 \mathrm{~h}$, dried and weighed (W1). It was then dipped in simulated dirt (1 g coconut oil and $1 \mathrm{~g}$ paraffin wax dissolved in $100 \mathrm{~mL}$ hexane). It was removed, dried and weighed (W2). The wool yarn was then placed in the shampoo (SP, SWP and SAFI) and shaken. It was taken out, rinsed in clean water, dried and weighed (W3). The cleaning was calculated as below:

$$
C(\%)=[(\mathrm{W} 2-\mathrm{W} 3) /(\mathrm{W} 2-\mathrm{W} 1) \times 100]
$$

\section{Stability testing}

The shampoo formulations were subjected to different storage conditions which is accelerated ageing $\left(45^{\circ} \mathrm{C}\right)$ and room temperature $\left(25^{\circ} \mathrm{C}\right)$ for 4 weeks. Before and after the storage, the shampoo formulations were inspected for their organoleptic characteristics (colour, smell, phase separation), viscosity and their $\mathrm{pH}$ value was determined (Mahmood et al., 2018).

\section{Antibacterial evaluation}

The active ingredient propolis extracts were subjected to in vitro testing using the disc diffusion method to evaluate its anti-bacterial activity against $S$. aureus.

\section{(i) Preparation of solution of active ingredient}

In $2.5 \mathrm{~g}$ of EEP powder was weighed and transferred to a $10 \mathrm{~mL}$ beaker of containing $10 \mathrm{~mL}$ of absolute DMSO. Then, the mixture was stirred quickly. Then, serial ten-fold dilution was made to make a stock solution of propolis with the concentration of $2500 \mu \mathrm{g} / \mathrm{mL}$ in $1 \%$ DMSO. Then, this stock solution was further diluted using ten-fold dilutions to make a concentration of propolis extract solution within the range of $0.25-2500 \mu \mathrm{g} / \mathrm{mL}$.

\section{(ii) Determination of MIC}

The broth microdilution method was used to determine the minimal inhibitory concentration (MIC) of ethanol extract of propolis solution and shampoo formulation as recommended by the National Committee for Clinical Laboratory Standard (NCCLS) (Klančnik et al., 2010). The concentrations of propolis extracts solution (PE) that has been tested on the growth of $S$. aureus are ranging from $2500-2.5 \mu \mathrm{g} / \mathrm{mL}$. The 96 -wellplate were filled with $10 \mu \mathrm{L}$ of overnight growing culture at turbidity of McFarland standard in the test well and added with $190 \mu \mathrm{L}$ of different concentration of propolis extract separately. Test wells were prepared in triplicate. Well for sterility control was prepared by filling only sterile broth medium in the well. The absorbance of each well was determined using an automatic tray reader adjusted at $630 \mathrm{~nm}$. The well plate was incubated for $24 \mathrm{~h}$ at $37^{\circ} \mathrm{C}$ with a rotation speed of $120 \mathrm{rpm}$. Then, the absorbance value in each test well was read again after incubation. These absorbance values were subtracted from those obtained before incubation. The MIC was defined as the minimum concentration of the solution required to inhibit the growth of bacteria.

\section{RESULTS AND DISCUSSION}

\section{Formulation of antidandruff shampoo from propolis extract}

Nowadays consumers expect for shampoos with unique functions which are far beyond the general functions. However, the majority of ingredients in synthetic shampoo 
have been under severe attack as it gives potential risk with its usage, like hair fall, allergic reactions to skin, weakening of the hair roots (Trüeb, 2007). Hence, people more prefer to use a shampoo with safer natural and naturally derived ingredients. In this study, we prepared a herbal antidandruff shampoo from propolis extract was introduced. This antidandruff shampoo was formulated by ingredients in a definite amount as shown in Table 1. Tween 80 , the surfactant in this formulation is a natural component that emulsifies the formulation and resists separation of the shampoo. It possesses good detergency and foaming properties. Propolis was used as an antidandruff agent in this shampoo as it contains bioflavonoid content in it which shows an antibacterial effect towards $S$. aureus bacteria (dandruff causing bacteria). A shampoo should have adequate viscosity to facilitate removal from the bottle but prevent drip down from hair during use (Patidar, 2018). Sodium carboxymethyl cellulose is a non-toxic ingredient that was used as a viscosity builder and stabilizer for the shampoo. Citric acid was added to adjust the $\mathrm{pH}$ to the desired level within the range. The formulated shampoo was further preserved with sodium benzoate in a small quantity which is safe to be used.

The yield of propolis extracts is higher by using maceration by ethanol where $58.16 \%$ yield obtained which is more than half of the initial weight of propolis can be obtained by this method, maceration by ethanol which uses ethanol at $70 \%$ of concentration. As the percentage of yield is more, it means that active compounds or amount of waxes that have been extracted also in a large amount (Trusheva et al., 2007).

\section{Organoleptic studies}

A shampoo like any other cosmetic preparation should have a good appealing physical appearance. The colour, odour and texture of the formulated shampoo with propolis extract (SP) were found to be acceptable (Al Badi and Khan, 2014). The formulated antidandruff shampoo gives a clear texture, herbal smell and yellowish orange colour. The sample SWP gave an unpleasant odour because it doesn't have any fragrance ingredient or propolis content in the formulation.

\section{Determination of $\mathrm{pH}$}

The $\mathrm{pH}$ value of shampoo is really vital for improving and enhancing the quality of the hair. Inappropriate $\mathrm{pH}$ value of shampoo can influence the tolerance at the skin and eye level. Table 2 shows that all the three shampoo's $\mathrm{pH}$ value fall between the range of 5 to 7 which is near to the skin $\mathrm{pH}$. The $\mathrm{pH}$ value for commercial shampoo found to be nearly neutral $(6.96 \pm 0.03)$. The sample SP $(6.12 \pm 0.01)$ is slightly acidic than the sample SWP $(6.37 \pm 0.02)$, this is due to the presence of propolis extract. High $\mathrm{pH}$ of shampoo which is too alkaline can cause dehydrative effect, irritability and can leave the hair dry and brittle.

\section{Determination of the percentage of solid content}

Percentage of the solid content of a shampoo determines the solid mass of material in the shampoo. Good quality of shampoo usually has $20 \%$ to $30 \%$ solid content (Al Badi and Khan, 2014). The percentage of solid content for all the tested shampoo was found to be within the range of $22 \%$ to $24 \%$. Since the values are within the expected range, it is proven that all the shampoos have the right amount of solid content where the shampoos are easy to be applied and rinsed out from the hair. If the shampoo contains a high content of solid, it will be hard to apply into the hair or difficult to wash out. The percentage of solid content found after the shampoo was dried for the SP sample is $22.63 \pm 0.08$. The percentage of solid content gained for the SWP sample and SAFI sample is $22.74 \pm 1.16$ and $23.23 \pm 0.71$, respectively (Table 2 ). The percentage of solid content in SP and SWP are almost equal due to the same formulation.

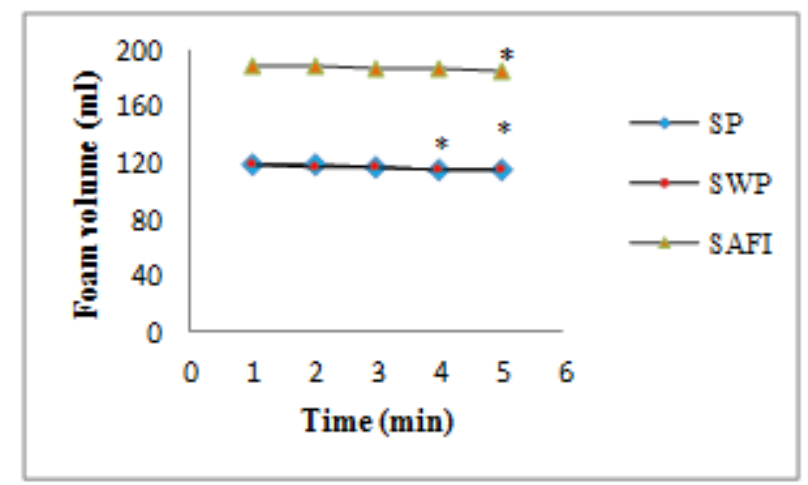

Figure 1: Foam retention profiles of shampoos (SP, SWP and SAFI), $n=3,{ }^{*} p<0.05$ was taken as significantly different at $1 \mathrm{~min}$ on their respective samples SP, SWP and SAFI.

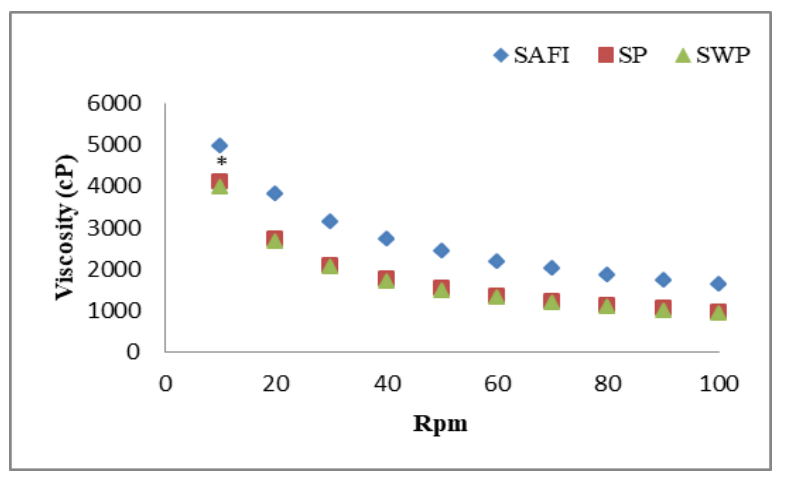

Figure 2: Result for the viscosity test for samples at different rpm (10-100 rpm), ${ }^{*} p<0.05$ was taken as significantly different from commercial shampoo (SAFI) at $10 \mathrm{rpm}$. 
Malays. J. Microbiol. Vol 16(1) 2020, pp. 49-57

DOI: http://dx.doi.org/10.21161/mjm.190368

Table 1: The compositions of formulation for anti-dandruff shampoo from propolis extract per bottle (100 $\mathrm{mL})$.

\begin{tabular}{|c|c|c|c|c|}
\hline \multirow{2}{*}{$\begin{array}{l}\text { Purpose } \\
\text { Diluent }\end{array}$} & \multirow{2}{*}{$\begin{array}{l}\text { Material } \\
\text { Distilled water }\end{array}$} & \multicolumn{2}{|c|}{ Percentage required } & \multirow[b]{3}{*}{ SAFI SHAMPOO } \\
\hline & & Qs to 100 & Qs to 100 & \\
\hline & & SP & SWP & \\
\hline Antibacterial & Propolis & 0.5 & Nil & $\begin{array}{l}\text { Zinc pyrithione, Nigella } \\
\text { sativa }\end{array}$ \\
\hline Surfactant & Tween 80 & 20.0 & 20.0 & Sodium lauryl sulphate \\
\hline Thickener & $\begin{array}{l}\text { Sodium } \\
\text { cellulose }\end{array}$ & 1.3 & 1.3 & $\begin{array}{l}\text { Hydroxypropyl } \\
\text { methylcellulose }\end{array}$ \\
\hline Stabilizer & $\begin{array}{l}\text { Ethylnediaminetetraacetic acid } \\
\text { (EDTA) }\end{array}$ & 0.05 & 0.05 & $\begin{array}{l}\text { Polyethelene } \\
\text { (PEG) }\end{array}$ \\
\hline Preservative & Sodium benzoate & 0.10 & 0.10 & Phenoxyethanol \\
\hline pH stabilizer & Citric acid & As needed & As needed & Sodium chloride \\
\hline
\end{tabular}

Table 2: Physico-chemical evaluation of formulated and commercial shampoo.

\begin{tabular}{lccc}
\hline & SP & SWP & SAFI SHAMPOO \\
\hline Colour & Yellowish orange & Colourless & Light blue \\
Odour & Herbal smell & Chemical smell & Floral smell \\
Texture & Clear & Clear & Milky opaque \\
$\mathrm{pH}(10 \%$ solution$)$ & $6.12 \pm 0.01^{*}$ & $6.37 \pm 0.02^{*}$ & $6.96 \pm 0.03$ \\
$\%$ solid contents & $22.63 \pm 0.08$ & $22.74 \pm 1.16$ & $23.23 \pm 0.71$ \\
Foam volume $(\mathrm{mL})$ & $119 \pm 1.73$ & $118 \pm 2.00$ & $190 \pm 2.00$ \\
Wetting time $(\mathrm{sec})$ & $46.10 \pm 4.17$ & $46.26 \pm 3.00$ & $44.66 \pm 2.32$ \\
\hline
\end{tabular}

Table 3: Stability studies of shampoo at room temperature and $45^{\circ} \mathrm{C}$ for 4 weeks.

\begin{tabular}{|c|c|c|c|}
\hline \multirow[t]{3}{*}{ Sample } & \multicolumn{3}{|c|}{ Storage condition } \\
\hline & \multirow{2}{*}{$\begin{array}{l}\text { Fresh samples } \\
\text { (Before storage) }\end{array}$} & \multicolumn{2}{|c|}{ Stability after 4 weeks } \\
\hline & & Accelerated aging $\left(45^{\circ} \mathrm{C}\right)$ & Room temperature $\left(25^{\circ} \mathrm{C}\right)$ \\
\hline \multicolumn{4}{|c|}{ 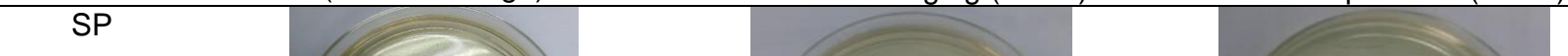 } \\
\hline Observation & $\begin{array}{l}\text { - The colour is yellowish } \\
\text { - The odour is good } \\
\text { - pH : } 6.47 \pm 0.01 \\
\text { - Viscosity : } 3502.87 \mathrm{cP}\end{array}$ & $\begin{array}{l}\text { - No change in colour } \\
\text { - The odour is good } \\
\text { - } \mathrm{pH}: 6.76 \pm 0.125 \\
\text { - Viscosity : } 5758.96 \mathrm{cP}\end{array}$ & $\begin{array}{l}\text { - No change in colour } \\
\text { - The odour is good } \\
\text { - } \mathrm{pH}: 6.9 \pm 0.045 \\
\text { - Viscosity : } 3317.43 \mathrm{cP}\end{array}$ \\
\hline \multicolumn{4}{|l|}{ SWP } \\
\hline Observation & $\begin{array}{l}\text { - The colour is clear } \\
\text { - The odour is not good } \\
\text { - pH : } 6.43 \pm 0.10 \\
\text { - Viscosity : } 3478.06 \mathrm{cP}\end{array}$ & $\begin{array}{l}\text { - No change in colour } \\
\text { - The odour is not good } \\
\text { - pH : } 6.76 \pm 0.112 \\
\text { - Viscosity : } 4643.61 \mathrm{cP}\end{array}$ & $\begin{array}{l}\text { - No change in colour } \\
\text { - The odour is not good } \\
\text { - pH : } 6.88 \pm 0.085 \\
\text { - Viscosity : } 3264.59 \mathrm{cP}\end{array}$ \\
\hline
\end{tabular}


Malays. J. Microbiol. Vol 16(1) 2020, pp. 49-57

DOI: http://dx.doi.org/10.21161/mjm.190368

Table 4: Measurement of inhibition area caused by active on the growth of $S$. aureus.

\begin{tabular}{ccccccc}
\hline \multirow{2}{*}{$\begin{array}{c}\text { Dilution } \\
\text { factor }\end{array}$} & \multicolumn{2}{c}{ The concentration of active in the sample } & \multicolumn{3}{c}{ Inhibition area $(\mathrm{mm})$} \\
\cline { 2 - 7 } & $\begin{array}{c}\mathrm{PE} \\
(\mu \mathrm{g} / \mathrm{mL})\end{array}$ & $\begin{array}{c}\mathrm{SP} \\
(\mu \mathrm{g} / \mathrm{mL})\end{array}$ & $\begin{array}{c}\text { SWP } \\
(\mathrm{g} / \mathrm{mL})\end{array}$ & $\mathrm{PE}$ & $\mathrm{SP}$ & SWP \\
\hline & 0.00 & 0.00 & 0.00 & $0.00 \pm 0.00$ & $0.00 \pm 0.00$ & $0.00 \pm 0.00$ \\
$10^{-4}$ & 0.25 & 0.25 & 0.001 & $0.00 \pm 0.00$ & $0.00 \pm 0.00$ & $0.00 \pm 0.00$ \\
$10^{-3}$ & 2.50 & 2.50 & 0.010 & $0.00 \pm 0.00$ & $0.00 \pm 0.00$ & $0.00 \pm 0.00$ \\
$10^{-2}$ & 25 & 25 & 0.100 & $0.00 \pm 0.00$ & $8.83 \pm 0.29^{*}$ & $0.00 \pm 0.00$ \\
$10^{-1}$ & 250 & 250 & 1.000 & $9.83 \pm 0.57^{*}$ & $10.33 \pm 0.58^{*}$ & $0.00 \pm 0.00$ \\
$10^{0}$ & 2500 & 2500 & 10.00 & $12.00 \pm 0.50^{*}$ & $12.67 \pm 0.29^{*}$ & $7.50 \pm 0.50^{*}$ \\
\hline
\end{tabular}

Each point is mean area, $\mathrm{n}=3,{ }^{*} p<0.05$ was taken as significantly different from the untreated group by one-way ANOVA

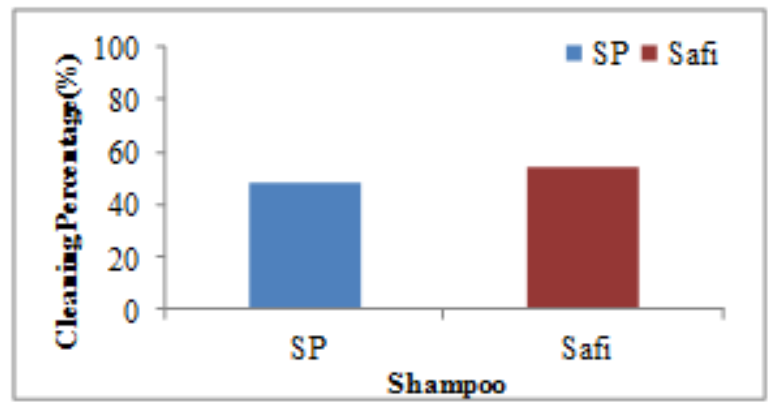

Figure 3: Cleaning ability of shampoo (SP and SAFI), $\mathrm{n}=3,{ }^{*} p<0.05$ was taken as significantly after soaked with simulated dirt on their respective samples SP and SAFI.

\section{Foaming ability and foaming stability test}

Foams or lathers are coarse dispersion of gas in a relatively small quantity of liquid generally containing a surfactant. The consumers make a judgement to the performance of the shampoo by looking at its foaming ability. As shown in Table 2, SP and SWP formulation have similar foaming ability whereas the commercial shampoo (SAFI) results in higher foaming ability. SAFI has higher foaming ability due to the presence of sodium lauryl sulphate (SLS) in its formulation which is an effective foaming agent. The foam volume for SAFI which reached up to $190 \pm 2.00 \mathrm{~mL}$ compared to foam volume of shampoo SP and SWP, which reached up to foam volume of $119 \pm 1.73 \mathrm{~mL}$ and $118 \pm 2.00 \mathrm{~mL}$, respectively. A lot of people have this misunderstanding that if the shampoo does not produce enough lather, it will not effectively clean up the hair. However, foaming doesn't have a great influence on the cleansing property of the product. All the tested shampoos retained their foam volume for 5 min showing that the shampoos have excellent foam stability. The foam retention ability of shampoo samples is shown in Figure 1. There is a significant difference in the values shown by the sample SP and SWP towards the SAFI sample.

\section{Viscosity test}

The viscosity of tested shampoos changes gradually as the rpm increases from 10 to $100 \mathrm{rpm}$. As the rpm increases, the viscosity of the samples decreases. This shows that the formulations are pseudoplastic in nature which is a desirable attribute for a shampoo formulation. The viscosity differences between the samples were observed and compared at a low rotation speed (10rpm) because the shear rates applicable to the flow of shampoo from the bottle are about 5-10 rpm. The viscosity value for all the samples at $10 \mathrm{rpm}$ is within the range of 3000-9000 cP (Moldovan and Părăuan, 2012). A shampoo should have good consistency, where the viscosity should be low enough to ensure a facile removal of shampoo from the package at the same time should be high enough to prevent them from reaching the eyes. Figure 2 shows the viscosity profile for each shampoo.

\section{Wetting time test}

Wetting test plays a vital role in the removal of the soil, oil and dye. Wetting phenomena are complicated and depend upon several factors such as diffusion, surface tension and the nature or characteristic of the surface being wetted. The main role of the wetting agent is to reduce surface tension. The results obtained for the wetting time test can be seen in Table 2 . The wetting time of three shampoos was found in the order $44.22<46.10$ $<46.26 \mathrm{~s}$ for SAFI, SP and SWP respectively. The disc in sample SAFI took the least time to sink followed by shampoo SWP and SP; this proves that the detergency level of shampoo SAFI is higher compared to shampoo SWP and SP. The commercial shampoo (SAFI) is made up of many chemical ingredients and surfactant which increased the detergency level, this causes the filter disc to take the least time to sink. The lower the time taken for the filter disc to sink showed the higher the detergency level of the shampoo. (AlQuadeib et al., 2018). High detergency level in shampoo enables it to remove dirt and sebum efficiently from the hair.

\section{Cleaning ability test}

The cleaning percentage determines the efficacy of the shampoo to remove the dirt from the hair (Pradhan and Bhattacharyya, 2014). The formulate shampoo, SP were compared with SAFI shampoo. The SP has a cleaning percentage of $48.42 \%$ and SAFI has a cleaning percentage of $53.94 \%$. SAFI gives better cleaning performance than SP because SP doesn't have 
Malays. J. Microbiol. Vol 16(1) 2020, pp. 49-57 DOI: http://dx.doi.org/10.21161/mjm.190368

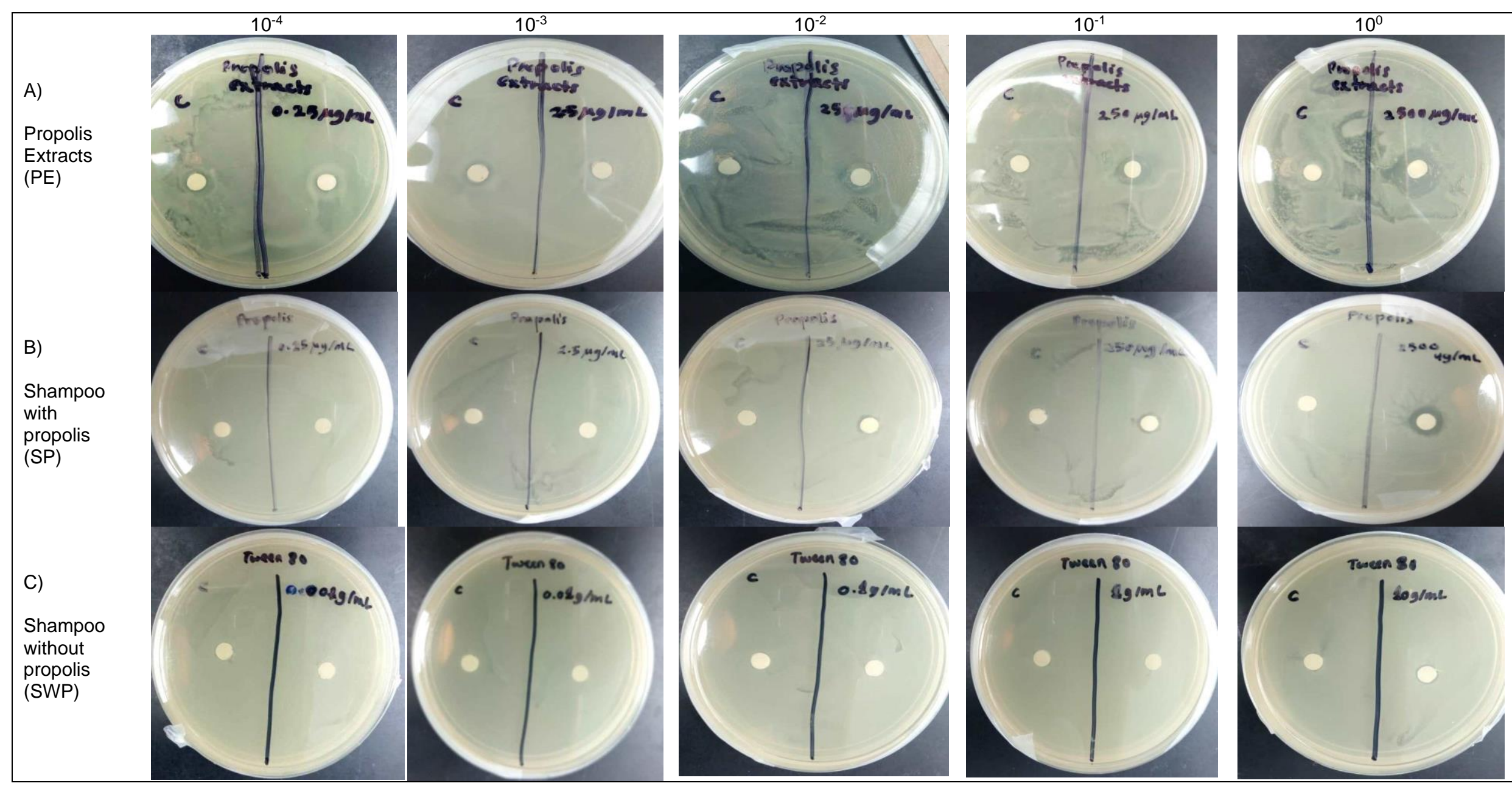

Figure. 4: Zones of inhibition of active against the growth of $S$. aureus at different concentration by ten-fold dilution. A) Propolis extracts (PE) B) Shampoo with propolis extracts (SP) C) Shampoo without propolis extracts (SWP) with dilution factor of: (i) $10^{-4}$ (ii) $10^{-3}$ (iii) $10^{-2}$ (iv) $10^{-1}$ (v) $10^{0}$ 
anionic surfactant in its formulation. SP sample could have an even better cleaning effect with the addition of cleaning surfactant in its formulation. The results for cleaning ability are shown in Figure 3.

\section{Stability testing}

The stability of shampoo was studied for 4 weeks at two different conditions which is at room temperature $\left(25^{\circ} \mathrm{C}\right)$ and accelerated ageing condition $\left(45^{\circ} \mathrm{C}\right)$. The result of the stability study is shown in Table 3 . The organoleptic characteristic of the samples no phase, colour remain same and the odour of the samples also remain unchanged throughout the storage after were tested under severe condition $\left(45^{\circ} \mathrm{C}\right.$ and $25^{\circ} \mathrm{C}$ ) for both SP and SWP shampoos. Thus, the sample can be said to be stable. The colour of the sample, SP which is yellowish orange from day 1 to day 15 remain unchanged. The result from $\mathrm{pH}$ testing shows no large variation of the shampoo. The shampoo remains at 5-7 pH which is suitable for this formulation. The viscosity value for all the samples at $10 \mathrm{rpm}$ is still within the acceptable range for a shampoo which is $3000-9000 c P$ (Moldovan and Părăuan, 2012). This indicated that the formulated shampoo remains stable and meet the requirements.

\section{Zone of Inhibition by the disc diffusion method}

The stock solution was prepared at $2500 \mu \mathrm{g} / \mathrm{mL}$ and diluted using ten-fold serial dilution method to give a different concentration of propolis extract (PE) solution, $0.25,2.5,25,250$, and $2500 \mu \mathrm{g} / \mathrm{mL}$. The shampoo formulation with propolis extracts (SP) was also been diluted by ten-fold serial dilution to make the concentration to be at the same concentration as the propolis extracts. Table 4 shows the measurement of the inhibition area caused by different formulations. The results show that for $\mathrm{PE}$ and $\mathrm{SP}$ starts inhibiting the growth of $S$. aureus at $250 \mu \mathrm{g} / \mathrm{mL}$ and $25 \mu \mathrm{g} / \mathrm{mL}$ respectively. This shows that the developed SP shampoo is 10 -fold more effective against dandruff causing bacteria compared to the propolis extracts alone. For both sample, $\mathrm{PE}$ and SP, activity against, $S$. aureus, the bacteria that causes dandruff, was also markedly higher at higher shampoo concentrations and no inhibition area detected at low concentration. This, therefore, implies that overdilution of the shampoo below the concentration of 25 $\mu \mathrm{g} / \mathrm{mL}$ is likely to reduce its efficacy during application in the process of washing the scalp and hair. As the concentration of propolis extracts solution increases, the zone of inhibition caused by that specific concentration on the growth of $S$. aureus also increases as shown in Figure 4. The zone of inhibition area was observed for SP is 8 $\mathrm{mm}$ at its lowest concentration $25 \mu \mathrm{g} / \mathrm{mL}$ compared to $\mathrm{PE}$ which needs $250 \mu \mathrm{g} / \mathrm{mL}$ with the range of $12-13 \mathrm{~mm}$. This can prove that propolis extracts exhibit antibacterial properties against $S$. aureus (de Lima et al., 2016). It is a desirable phenomenon as the dandruff problems in human is mainly caused by the growth of $S$. aureus. The reason for increases in antibacterial effect for SP is due to the presence of Tween 80 as a surfactant in the shampoo formulations. According to the data in Table 4, it is evident that Tween 80 also exhibits antibacterial properties at the concentration of $10 \mathrm{~g} / \mathrm{mL}$ and above. The measurement on the inhibition area caused by different sample at different concentration can be seen more clearly in Figure 5. This was also further supported by earlier studies where Tween 80 exhibits antibacterial properties beyond the concentration of $4 \%$ (Rebello et al., 2014). Without any expectation at the beginning of this study, surprisingly, the developed formulation shows a dual effect of antibacterial against $S$. aureus due to the addition of Tween 80 as a surfactant. This will be a desirable condition for consumers as it will work more effectively in treating dandruff problem in human.

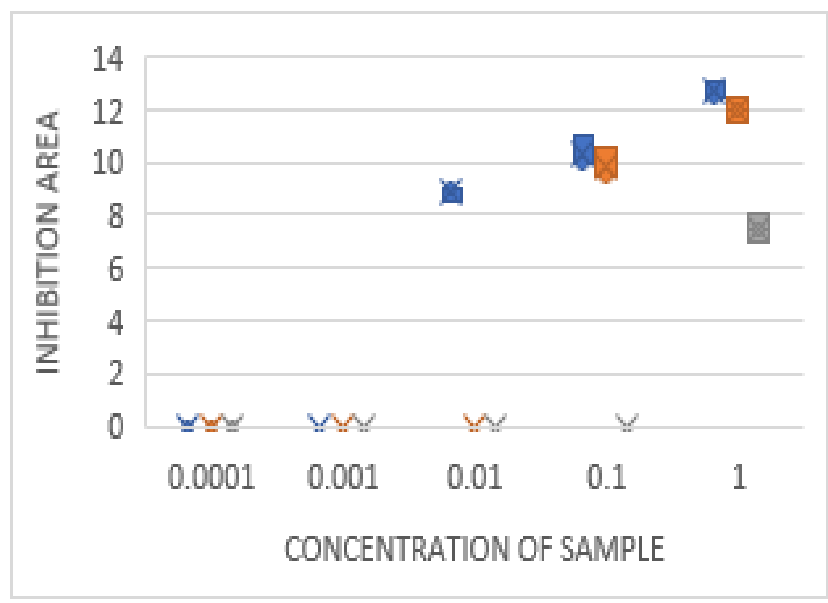

Figure 5: Measurement of inhibition area caused by different sample, SP, PE and SWP at different concentration by 10 -fold dilutions.

\section{Determination of MIC by broth microdilution}

Broth microdilution method was used to determine the MIC of propolis extracts solution and shampoo formulation for more accurate results. The MIC is the lowest concentration of propolis extracts solution and shampoo formulation that needed to inhibit the growth of dandruff causing bacteria. Comparing to the disc diffusion method which uses ten-fold dilution of $\mathrm{PE}$ solution and $\mathrm{SP}$, MIC value that obtained is $250 \mu \mathrm{g} / \mathrm{mL}$ and $25 \mu \mathrm{g} / \mathrm{mL}$, respectively. However, the broth microdilution method gives a lower MIC value for both samples compared to the disc diffusion method. According to the broth microdilution method, the MIC value for PE and SP is $39.063 \mu \mathrm{g} / \mathrm{mL}$ and $19.53 \mu \mathrm{g} / \mathrm{mL}$ respectively. This shows that the lowest concentration that needed by developed shampoo to inhibit the growth of dandruff causing bacteria, $S$. aureus is lower than the lowest concentration needed by propolis extracts. This is another 44 evidence that the developed shampoo works better in treating against dandruff-causing bacteria, $S$. aureus compared to the propolis extracts alone. 


\section{CONCLUSION}

The main aim behind this research was to formulate a stable and functionally effective antidandruff herbal shampoo by excluding synthetic active ingredients which are normally incorporated in such formulation for the antidandruff agent and make use of natural sources, that is propolis extracts as the antibacterial agent. This work has shown that the development of this shampoo is able to treat the most common bacteria $S$. aureus which causes dandruff problem on the human scalp. The propolis extracts show the antibacterial effect at lower concentration towards the growth of $S$. aureus. Interestingly, the developed shampoo with the propolis extracts shows a much 10-fold better antibacterial effect compared to the antibacterial effect of the propolis extracts itself. This is due to the presence of Tween 80 as the surfactant used in the formulation which adds to this antibacterial effect. This means that the developed shampoo shows a dual effect on antibacterial activity, therefore it is evident that the developed shampoo is able to treat dandruff in human more effectively. However, further studies need to be conducted on different dandruff causing bacteria and fungus in order to prove the safety and efficacy of this formulation to combat dandruff problems.

\section{ACKNOWLEDGEMENTS}

This work was financially supported by a Research Grant (Project No. RDU150379 and RDU1803181) from Universiti Malaysia Pahang (www.ump.edu.my) and Fundamental Research Grant Scheme (FRGS/1/2017/TK05/UMP//1) from Ministry of Higher Education (MoHE), Malaysia for which the authors are very grateful.

\section{REFERENCES}

Al Badi, K. and Khan, S. A. (2014). Formulation, evaluation and comparison of the herbal shampoo with the commercial shampoos. Beni-Suef University Journal of Basic and Applied Sciences 3(4), 301-305.

AIQuadeib, B. T., Eltahir, E. K., Banafa, R. A. and AlHadhairi, L. A. (2018). Pharmaceutical evaluation of different shampoo brands in local Saudi market. Saudi Pharmaceutical Journal 26(1), 98-106.

Borda, L. J. and Wikramanayake, T. C. (2015). Seborrheic dermatitis and dandruff: A comprehensive review. Journal of Clinical and Investigative Dermatology 3(2).

Cardoso, R. L., Maboni, F., Machado, G., Sydney, H. A. and Agueda, C. D. E. (2010). Antimicrobial activity of propolis extract against Staphylococcus coagulase positive and Malassezia pachydermatis of canine otitis. Veterinary Microbiology 142(3-4), 432-434.

Chaijan, M. R., Handjani, F., Zarshenas, M., Rahimabadi, M. S. and Tavakkoli, A. (2018). The Myrtus communis L. solution versus ketoconazole shampoo in treatment of dandruff: A double blinded randomized clinical trial. Journal of Pakistan Medical Association 68(5), 715-720.

Chen, Y. W., Ye, S. R., Ting, C. and Yu, Y. H. (2018). Antibacterial activity of propolins from Taiwanese green propolis. Journal of Food and Drug Analysis 26(2), 761-768.

de Lima, G. G., de Souza, R. O., Bozzi, A. D., Poplawska, M. A., Devine, D. M. and Nugent, M. J. (2016). Extraction method plays critical role in antibacterial activity of propolis-loaded hydrogels. Journal of Pharmaceutical Sciences 105(3), 1248-1257.

Elnakady, Y. A., Rushdi, A. I., Franke, R., Abutaha, N., Ebaid, H., Baabbad, M. and Al Ghamdi, A. A. (2017). Characteristics, chemical compositions and biological activities of propolis from Al-Bahah, Saudi Arabia. Scientific Reports 7, 41453.

Honnavar, P., Chakrabarti, A., Prasad, G. S., Singh, P., Dogra, S. and Rudramurthy, S. M. (2017). $\beta$ Endorphin enhances the phospholipase activity of the dandruff causing fungi Malassezia globosa and Malassezia restricta. Medical Mycology 55(2), 150154.

Mahmood, S., Mandal, U. K. and Chatterjee, B. (2018). Transdermal delivery of raloxifene $\mathrm{HCl}$ via ethosomal system: Formulation, advanced characterizations and pharmacokinetic evaluation. International Journal of Pharmaceutics 542(1-2), 36-46.

Moldovan, M. and Părăuan, S. (2012). Cosmetic evaluation of some commercial shampoos. Farmacie Clujul Medical 85(3), 378-383.

Othman, A. A., Balila, R. M., Mahdi, S. I. and Ahmed, M. E. (2016). Healing potential of propolis and bee's honey on diabetic foot ulcers in Jabir Abu Eliz Diabetic Center-Khartoum. Sudan Medical Journal 11(3687), 14.

Patidar, K. (2018). Development of polyherbal shampoo for antifungal activity and its comparison with commercially available shampoo: A research article. Asian Journal of Pharmaceutics 12(03).

Pradhan, A. and Bhattacharyya, A. (2014). Shampoos then and now: Synthetic versus natural. Journal of Surface Science and Technology 30(1-2), 59-76.

Rebello, S., Asok, A. K., Mundayoor, S. and Jisha, M. S. (2014). Surfactants: toxicity, remediation and green surfactants. Environmental Chemistry Letters 12(2), 275-287.

Silici, S. and Kutluca, S. (2005). Chemical composition and antibacterial activity of propolis collected by three different races of honeybees in the same region. Journal of Ethnopharmacology 99(1),69-73.

Sosmowski, Z. M. (1983). U.S. Patent No. 4,382,886. Washington, DC: U.S. Patent and Trademark Office.

Trüeb, R. M. (2007). Shampoos: Ingredients, efficacy and adverse effects. Journal der Deutschen Dermatologischen Gesellschaft 5(5), 356-365.

Trusheva, B., Trunkova, D. and Bankova, V. (2007). Different extraction methods of biologically active components from propolis: A preliminary study. Chemistry Central Journal 1(1), 13. 